\title{
Pengembangan dan Sosialisasi Aplikasi E-Commers Parea di KUBE Sekar Muria Hadipolo Kudus
}

\author{
Diana Laily Fithri ${ }^{1}$, Andy Prasetyo Utomo ${ }^{2}$, Fajar Nugraha ${ }^{3}$ \\ ${ }^{123}$ Universitas Muria Kudus \\ *Email : Diana.Laily@umk.ac.id, Andy.Prasetyo@umk.ac.id,Fajar.nugraha@umk.ac.id*
}

\begin{abstract}
Hadipolo Village is one of the villages in Jekulo District, Kudus Regency. In this village there are several bitter melon farmers who process it into snacks that are nutritious and very beneficial for health. So far, the marketing process for bitter melon chips is still done traditionally so that sales of bitter gourd chips are not optimal in quantity and the range of promotions is still limited around the city of Kudus, although there are some requests from outside the city but the numbers are still large. still a little because of lack of promotion. The purpose of this community service is to develop and socialize e-commerce applications which are expected to help and increase the income and welfare of the bitter melon chip craftsmen in Hadipolo Village. With a specific target in the use of Pare e-commerce, namely increasing the marketing quantity of bitter gourd chips by expanding the marketing area by promoting the results of bitter melon chips through ecommerce so that they can reach a wider market. Pare e-commerce is an e-commerce used by Kube Pare chips in developing and marketing products from Pare chips. The way this system works is by conducting online buying and selling transactions, so that the marketing area is also wider.

Keywords: bitter melon, promotion, E-commerce.
\end{abstract}

Keywords: Pare, Promotion, E-Commerce.

\begin{abstract}
Abstrak
Desa Hadipolo merupakan salah satu desa yang berada di Kecamatan Jekulo Kabupaten Kudus. Di desa ini terdapat beberapa petani pare yang mengolahnya menjadi makanan ringan yang berkhasiat dan sangat bermanfaat bagi kesehatan. Selama ini proses pemasaran keripik pare masih dilakukan secara tradisional sehingga penjualan keripik pare secara kuantitas belum maksimal dan jangkauan promosi masih terbatas di sekitar kota Kudus, walaupun ada beberapa permintaan dari luar kota namun jumlahnya masih banyak. masih sedikit karena kurang promosi. Tujuan dari pengabdian masyarakat ini adalah untuk pengembangan dan sosialisasi aplikasi e-commerce yang diharapkan dapat membantu dan meningkatkan pendapatan, kesejahteraan para pengrajin keripik pare di Desa Hadipolo. Dengan target khusus dalam penggunaan e-commerce Parea yaitu meningkatkan kuantitas pemasaran keripik pare dengan memperluas wilayah pemasaran dengan mempromosikan hasil keripik pare melalui e-commerce sehingga dapat menjangkau pasar yang lebih luas. E-commerce Parea merupakan e-commerce yang digunakan Kube keripik pare dalam mengembangkan dan memasarkan produk dari keripik Pare tersebut. Cara kerjanya dari sistem tersebut adalah dengan melakukan transaksi jual beli secara online, agar wilayah pemasaran juga semakin luas.
\end{abstract}

Kata kunci : Pare, Promosi, E-Commerce.

\section{PENDAHULUAN}

Di kecamatan Jekulo tepatnya di desa Hadipolo terdapat beberapa pembudidaya serta beberapa unit usaha kecil yang memproduksi makanan ringan keripik hasil pengolahan buah pare. Selama ini, karena peralatan produksi masih sederhana khususnya dalam proses penggorengan yang masih dilakukan secara manual, yaitu dengan kompor gas dan wajan besar. Sistem penggorengan dengan cara manual seperti ini banyak sekali kekurangannya, baik secara kualitas maupun kuantitasnya. Secara kualitas antara lain rasanya yang masih pahit, dan gizinya yang telah banyak berkurang. Walaupun sebagian masyarakat masih menyukai rasa pahit ini, tetapi 
sebagian lainnya menginginkan rasa pahitnya hilang. Secara kuantitas, proses penggorengan tradisional memakan waktu yang tidak sedikit. Para pengrajin keripik pare selama ini hanya mampu mengolah sebanyak 50 kilogram hingga 60 kilogram keripik buah pare per harinya. Proses produksi keripik pare yang memakan waktu dan melalui beberapa tahapan tersebut berdampak pada proses pemasaran yang belum optimal, para pengrajin selama ini terfokus pada proses produksi tersebut, sehingga dalam segi promosi maupun pemasaran produk belum dikelola secara baik. Promosi serta pemasaran produk hasil keripik pare masih terbatas dari mulut ke mulut di wilayah lokal kabupaten Kudus. Sumber daya yang dimiliki belum mampu memperkenalkan produk hasil ke luar daerah Kudus karena keterbatasan waktu dan biaya. Berhubungan dengan promosi yang perlu diperluas, maka tim kami membantu dengan cara membuatkan serta mengembangkan aplikasi e-commerce Parea serta melakukan sosialisasi sebagai media promosi online. Pengembangan aplikasi serta Sosialisasi di Kube keripik pare Parea dewasa ini dirasa paling efektif karena pengembangan aplikasi e-commerce Parea ini berupa mengembangkan website sendiri sebagai sarana promosi serta pemasaran produk keripik pare. Diharapkan dengan adanya pengabdian masyarakat melalui program Ipteks bagi masyarakat ini bisa meningkatkan kuantitas pemasaran produk keripik pare ini. Sehingga pada akhirnya pendapatan dan kesejahteraan para pengrajin keripik pare ini dapat meningkat dengan lebih baik lagi.

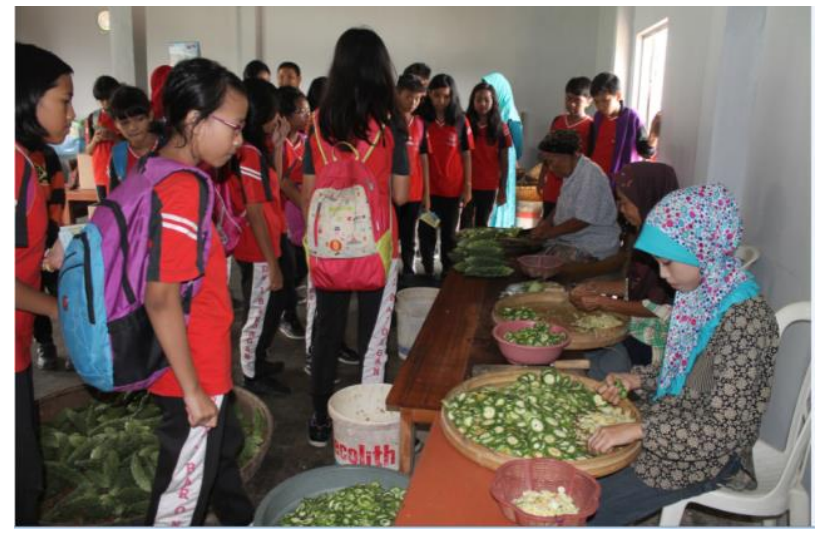

\section{Gambar 1 : Proses pembuatan keripik pare Kube Sekar Muria Hadipolo Kudus}

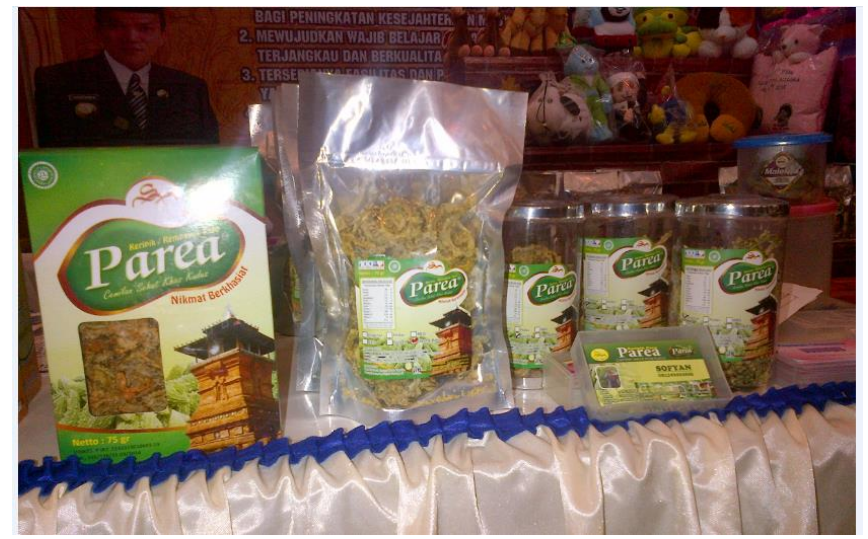

Gambar 2 : Produk Kube Sekar Muria Hadipolo

E-Commerce termasuk salah satu istilah pada "perdagangan elektronik" yang berubah sejalan dengan waktu. E-Commerce di Indonesia pada era globalisasi ini semakin berkembang pesat. Perkembangan teknologi komunikasi dan komputer menyebabkan terjadinya perubahan kultur kita sehari-hari. Dalam era yang disebut "information age" ini, media elektronikmenjadi salah satu media andalan untuk 
melakukan komunikasi dan bisnis.(Harimurti \& Sutanto, 2014). Banyak aplikasi yang dapat mendukung dalam proses penjualan online, terutama aplikasi OLX dan pemasaran online melalui portal e-commers (Desyanti, Febrina Sari, Wetri Febrina 2021). Meningkatnya pengguna internet lebih memudahkan customer dalam memudahkan dalam transaksi jual beli, mendorong munculnya suatu tuntutan pelayanan internet melebihi dari apa yang bisa diperoleh di dunia nyata. Ini meliputi kesempatan untuk menjual barang-barang komoditi secara online. sistem berbasis $E$ commerce yang memfokuskan diri pada transaksi bisnis berbasis individu dengan menggunakan internet ( teknologi berbasis jaringan digital) dengan aplikasi $E$ commerce transaksi dapat dilakukan dengan lebih cepat dan lebih intensif. (Sidik, 2019)

Penggunaan media internet khususnya e-commerce akan mempermudah, memperluas dan meningkatkan akses, jangkauan serta layanan kepada pelanggan.Kemajuan teknologi komputer, multimedia dan smartphone memberi peluang besar bagi pengusaha Usaha Kecil khususnya pengusaha kuliner makanan dan minuman tradisional. (Wirdiani et al., 2020) Tujuan kegiatan pengabdian masyarakat ini yaitu sosialisasi kegiatan penggunaan aplikasi E-commerce sebagai aplikasi penjualan online. Dengan adanya website informasi akan dapat membantu masyarakat untuk mendapatkan informasi aktual seputar produk yang dijual, promopromo, pengetahuan dan kegiatan-kegiatan di Home Industri.(BOURKE, 2011). Tidak hanya memanfaatkan internet sebagai alat untuk melakukan promosi atau mencari peluang bisnis, tetapi juga harus diimbangi dengan pengelolaan administrasi yang baik melalui penggunaan software yang tepat. Sebagai upaya mengembangkan bisnis, banyak hal yang perlu dilakukan, salah satunya adalah dengan menerapkannya sistem e-commerse. E-commerse dalam dunia usaha adalah penggunaan tekhnologi terkini seperti internet dalam memudahkan kegiatan-kegiatan bisnis. Melalui internet pelaku usaha dapat dengan mudah berkomunikasi dan surat menyurat melalui email, chating, dan lain sebagainya. Dapat mempromosikan produk melalui iklan online, juga dapat memperkenalkan perusahaan dan mencari pelanggan baru melalui laman (website)(Di et al., 2020)

Memandang manfaat penerapan e-commerce tersebut, maka Kube Sekar Muria Hadipolo Kudus ingin bekerja sama dengan Universitas Muria Kudus dalam hal ini diwakili oleh dosen program studi Sistem Informasi untuk mengadakan pelatihan pengembangan dan implementasi e-commerce tersebut. Terdapat empat konsep dasar strategi pemasaran Kotler diantaranya Product, Price, Place, dan Promotion. Dalam Cangara (2014) David J. Rahman menyatakan bahwa prinsip pemasaran komersial, yakni proses perencanaan dan penetapan harga, promosi dan penyebaran ide-ide, barang dan layanan jasa untuk menciptakan pertukaran guna memenuhi kepuasan individu atau tujuan organisasi. Atas dasar tersebut maka pemasaran harus digerakkan oleh empat elemen dasar perencanaan komunikasi dalam rangka pencitraan produk untuk mengarah pada bagaimana khalayak bisa menjadi konsumen yang disebut sebagai bauran pemasaran (marketing mix).

\section{METODE}

Salah satu implementasi teknologi informasi bagi usaha mikro kecil dan menengah (UMKM) untuk penjualan produk adalah pemanfaatan teknologi $e$ commerce. Kube Sekar Muria merupakan kelompok usaha yang memproduksi makanan ringan keripik pare. Kedua kelompok usaha tersebut pada saat ini dalam memasarkan produk yang dihasilkannya belum memanfaatkan teknologi informasi, sehingga lingkup pemasaran masih bersifat lokal. Pemanfaatan teknologi informasi (e-commerce) diharapkan dapat membantu untuk mempromosikan dan meningkatkan penjualan hasil produksi, karena lingkup pemasaran akan semakin meluas. Hasil 
ABDINE: Jurnal Pengabdian Kepada Masyarakat Vol. 1, No.2, Desember2021,Hal.184-189 p-ISSN 2798-2882, e-ISSN 2798-2890

penelitian dapat mendukung proses pemasaran produk sehingga pada akhirnya akan meningkatkan omset penjualan produk. Sistem e-commerce ini dirancang menggunakan pemodelan UML (Unified Modeling Language), untuk pengelolaan database menggunakan DBMS (Database Management System) MySQL.

Metode pengembangan sistem yang digunakan dalam proses ini adalah Waterfall Method. Kegiatan yang dilaksanakan didasarkan pada tahap-tahap berikut;

1. Analisis Kebutuhan Perangkat Lunak

Proses pengumpulan kebutuhan secara intensif untuk menspesifikasikan kebutuhan perangkat lunak agar dipahami oleh pengguna.

2. Desain

Proses multilangkah yang fokus pada desain pembuatan program perangkat lunak termasuk struktur data, arsitektur perangkat lunak, representasi antarmuka dan prosedur pengkodean.

3. Pengkodean

Desain diterjemahkan ke dalam program perangkat lunak.

4. Pengujian

Proses yang dilakukan untuk meminimalisir kesalahan (error) dan memasukkan keluaran yang dihasilkan sesuai dengan keinginan.

5. Pemeliharaan

Mengulangi proses pengembangan mulai dari analisis spesifikasi untuk perubahan perangkat lunak yang sudah ada, tapi tidak untuk membuat perangkat lunak baru.

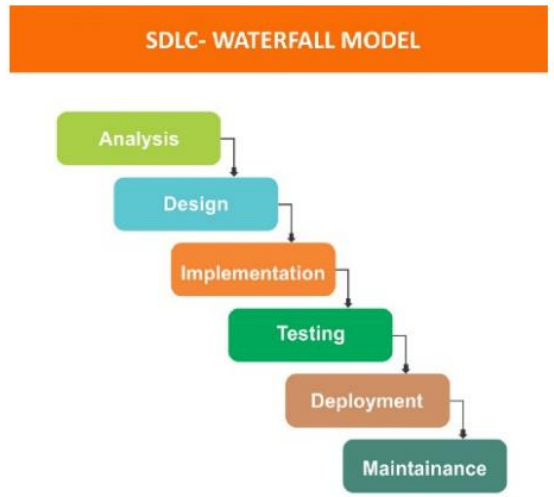

Gambar 3 : Bagan alir diagram waterfall model

\section{HASIL DAN PEMBAHASAN}

Pengembangan dan implementasi e-commerce Parea untuk proses promosi serta pemasaran produk keripik pare telah berhasil diberdayagunakan setelah melalui proses dari awal pengenalan aplikasi e-commerce sampai dengan implementasinya. Proses awal tersebut dimulai dari analisa dan perancangan sistem, pengembangan sistem, penerapan sistem serta tahap evaluasi sistem.

Hasil kegiatan pengabdian pada masyarakat ini berupa pengembangan aplikasi ecommerce Parea serta sosialiasi telah sesuai dengan rancangan dan rencana evaluasi. Salah satu implementasi dari kegiatan pengabdian ini adalah sudah diterapkannya pengembangan media promosi serta pemasaran berbasis e-commerce. 
ABDINE: Jurnal Pengabdian Kepada Masyarakat Vol. 1, No.2, Desember2021,Hal.184-189 p-ISSN 2798-2882, e-ISSN 2798-2890

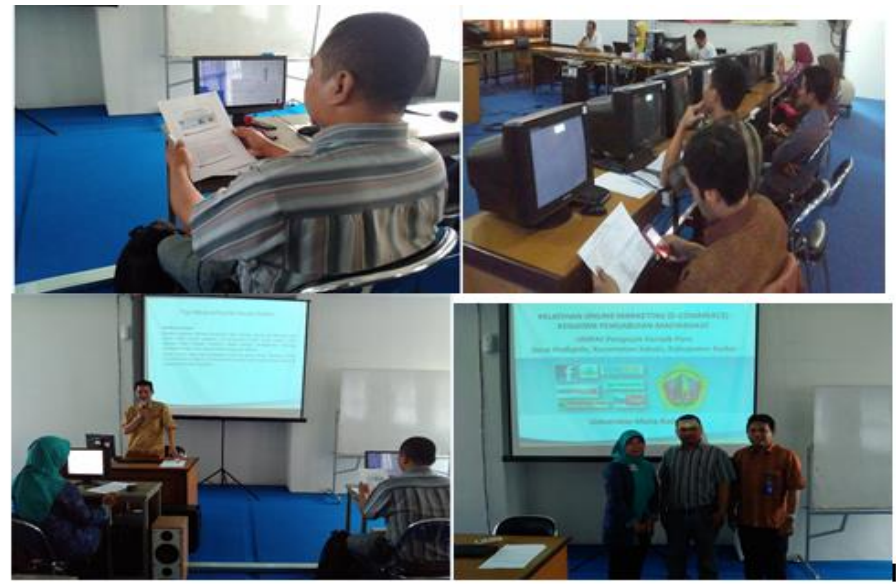

\section{Gambar 4 : Pelatihan dan sosialisasi e-commerce Parea Kube Sekar Muria Hadipolo}

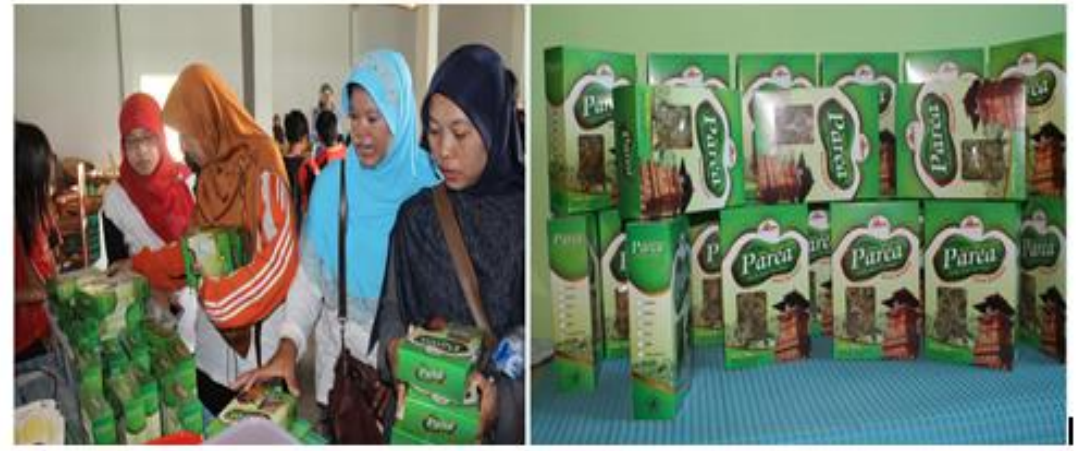

Gambar 5 : Proses jual beli dan produk keripik Pare Parea

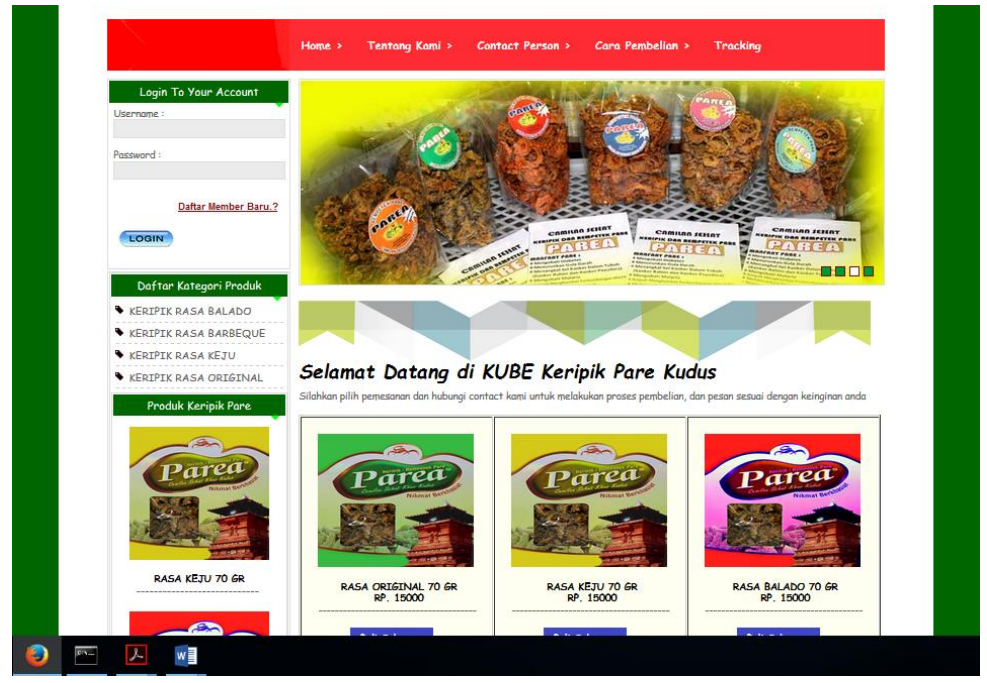

Gambar 6 : E-Commerce Parea Sebagai Promosi Dan Pemasaran Keripik Pare

Selain penguasaan teori mengenai pengembangan media promosi dan pemasaran berbasis e-commerce Parea dengan baik, target mendapatkan keterampilan penerapan secara langsung melalui praktek dalam implementasi e-commerce untuk kegiatan promosi serta pemasaran produk. 
ABDINE: Jurnal Pengabdian Kepada Masyarakat Vol. 1, No.2, Desember2021,Hal.184-189 p-ISSN 2798-2882, e-ISSN 2798-2890

Meskipun penerapan sistem sudah berjalan dengan baik dan sesuai perencanaan, namun masih terdapat beberapa hal yang menjadi catatan dalam kegiatan pengabdian pengembangan dan implementasi e-commerce Parea pada Kube Sekar Muria Hadipolo Kudus ini antara lain:

1. Untuk khalayak sasaran pengabdian masih diperlukan pelatihan kembali oleh pihak pengguna dikarenakan banyaknya menu yang terdapat pada e-commerce, agar dapat memahami fungsi atau setting pada media e-commerce agar dapat berfungsi secara optimal.

2. Implementasi pengembangan media promosi serta pemasaran berbasis e-commerce juga diperlukan sebuah perangkat untuk koneksi internet yang baik agar pemanfaatan sistem tersebut dapat digunakan secara optimal dalam kegiatan promosi dan pemasaran produk.

\section{KESIMPULAN}

Tanggapan khalayak, sasaran atau target pengabdian sangat baik dengan kegiatan pengabdian pengembangan dan implementasi e-commerce ini dikarenakan dapat membantu dalam proses promosi dan pemasaran produk pada Kube Sekar Muria Hadipolo Kudus.

Pelatihan pengembangan dan implementasi aplikasi e-commerce ini diberdayagunakan setelah melalui proses dari awal yang meliputi analisa dan perancangan sistem, pengembangan sistem, penerapan sistem serta tahap evaluasi sistem. Pada proses pelatihan implemantasi e-commerce dilakukan melalui kegiatan pemahaman pengenalan aplikasi e-commerce, konfigurasi aplikasi, pengelolaan sistem serta tahap akhir berupa evaluasi kegiatan pengabdian

\section{DAFTAR PUSTAKA}

BOURKE, J. (2011). Home Industries. Husbandry to Housewifery, 15(1), 109-141. https://doi.org/10.1093/acprof:oso/9780198203858.003.0005

Di, U., Kelurahan, R. W., \& Kecamatan, T. (2020). Kata Kunci: 4(2), 99-105.

Desyanti D, Febrina Sari, Wetri Febrina, M.A., 2021. Peningkatan Minat dan Skill Kewirausahaan Mayarakat di Kelurahan Bukit Batrem , Kota Dumai. Masyarakat Berdaya dan Inovasi, 2(2), pp.150-158.

Harimurti, R. M. A., \& Sutanto, Y. (2014). Pengembangan Aplikasi E-Business Untuk Manajemen Penjualan Menggunakan Sms Gateway Berbasis Web. Jurnal Penelitian Pos Dan Informatika, 4(1), 37-86. https://jurnalppi.kominfo.go.id/index.php/jppi/article/view/040104/15

Nugroho, Adi. (2011). Perancangan dan Implementasi Sistem Basis Data, Yogyakarta: Andi

Sidik, M. (2019). Perancangan dan Pengembangan E-commerce dengan Metode Research and Development. Jtiust, 04(1), 99-107.

Shalahuddin, Muhammad, Rosa Ariani S. (2011). Modul Pembelajaran Rekayasa Perangkat Lunak Terstruktur dan Berientasi Objek, Bandung: Modula.

Sholiq. (2006). Permodelan Sistem Informasi Berorientasi Obyek dengan UML, Yogyakarta : Graha Ilmu. 40-105.

Suhendar, A., Gunadi, H. (2002). Visual Modelling Menggunakan UML dan Rational Rose, Bandung: Informatika.

Wirdiani, N. K., Sudana, A. A. K. O., Rusjayanthi, N. K. D., \& Githa, D. P. (2020). Pelatihan Dan Sosialisasi E-Commerce Usaha Kecil Kuliner Di Kelurahan Padangsambian. Buletin Udayana Mengabdi, 19(1), 106-113. https://doi.org/10.24843/bum.2020.v19.i01.p20 